\title{
Effect of rhizobium, VAM and rock phosphate inoculation on growth and productivity and isolation of VAMF spores of Pisum sativum
}

\author{
Tabassum Yaseen ${ }^{1 *}$, Farrukh Hussain ${ }^{2}$ and Muhammad Shakeel ${ }^{3}$ \\ 1. Department of Botany, Bacha Khan University, Charsadda KPK-Pakistan \\ 2. Department of Microbiology and Biotechnology, Sarhad University of Science and Information Technology, \\ Peshawar-Pakistan \\ 3. Department of Biotechnology, Bacha Khan University of Charssada KPK-Pakistan \\ *Corresponding author's e-mail: sciences111@yahoo.com \\ Citation \\ Tabassum Yaseen, Farrukh Hussain and Muhammad Shakeel. Effect of rhizobium, VAM and rock phosphate \\ inoculation on growth and productivity and isolation of VAMF spores of Pisum sativum. Pure and Applied Biology. \\ Vol. 5, Issue 3, pp564-572. http://dx.doi.org/10.19045/bspab.2016.50072
}

\begin{tabular}{llll}
\hline \hline Received: 17/02/2016 & Revised: 11/05/2016 & Accepted: 10/06/2016 & Online First: 17/06/2016 \\
\hline \hline
\end{tabular}

\section{Abstract}

Rhizobium, VAM and rock phosphate inoculation has a significant utilization in Pisum sativum. The present study was conducted to study the influence of rock phosphorus fertilization, Vesicular Arbuscular Mycorrhizae (VAM) and rhizobium inoculation on growth and yield parameters of Pisum sativum. The experiment was laid out in randomized complete block design during summer season at the Department of Botany University of Peshawar Pakistan. A composite soil sample was collected for analysis of soil for physical and chemical properties. Rock phosphorus fertilization, application along with AMF and rhizobium inoculation increased the growth parameters significantly. Inoculation under Phosphors deficient soil which have pivotal role in the mycorrhization, growth and productivity. Dual inoculation, Rhizobium and AMF resulted in an increase in grain yield respectively, over no inoculation in Pisum sativum. Maximum growth was observed where AMF along with rhizobium and rock phosphate inoculation were applied. It is concluded that Pisum sativum should preferably be grown with dual inoculation of VAM along with rhizobium and rock phosphate. And vesicular arbuscular mycorrhizal spores in the rhizospheric soils of Pisum sativum at three different stages, vegetative, flowering and fruiting highest spores density recorded at fruiting stage and increased with the age of plant and also effected by the treatment highest in dual inoculation as comapared to single inoculation.

Key words: Arbuscular mycorrhizae fungi; RP fertilizer; AMF spores; Glomus spp; Clerocyctis; Aculospora

\section{Introduction}

Arbuscular mycorrhizas (AM) are widespread symbiotic interactions that are commonly described as the result of coevolution between fungi and plants where both partners benefit from the reciprocal nutrient exchange [1]. Arbuscular mycorrhizal (AM) symbioses are formed by approximately $80 \%$ of vascular plant species in all major terrestrial biomes [2-3]. 
Dual inoculation with both microorganisms results in a tripartite mutualistic symbiosis and generally increases plant growth to a greater extent than inoculation with only one [4]. Inoculation alone or a combination of beneficial microorganisms including AMF, rhizobia, PGPR and PSB (Phosphate Solubilizing Bacteria) have been shown to increase green gram and chickpea growth and productivity, nitrogen fixation and nutrient uptake[5-14]. The AMF inoculation, alone or in combination with rhizobial inoculation, resulted in large increases in yield, root colonization and phosphorus content of the seed and shoot [15].

The present studies were conducted to evaluate the beneficial effect of bio-fertilizers (VAM, Rhizobium and Rock phosphate) inoculation alone and in combination on growth, productivity and spore density of Pisum sativum.

\section{Materials and methods}

The present study was conducted during summer at the Department of Botany University of Peshawar Pakistan. Seeds of Pea (Pisum sativum) were sown in circular earthen pots $(21 \mathrm{~cm}$ height and $70.6 \mathrm{~cm}$ diameter) filled with a mixture of soil which was sterilized in Laboratory of Soil and Environmental Department of Agricultural University and was mixed with sand in ratio of 2:1 (v/v. Rhizobia and AMF propagules mixed. Rhizospheric soil from wheat field having high spore number of different AMF i-e Glomus fasciculatum, G. mosseae and G. aggregatum and roots of wheat and maize infected with Arbuscular mycorrhiza were used as rhizobase inoculum. The root pieces along with soil base inoculum (rhizospheric soil) were spread uniformly in layers at a depth of $3 \mathrm{~cm}$ and $6 \mathrm{~cm}$ before sowing. Inoculum for each pot consisted of $180 \mathrm{~g}$ of mycorrhizal infected roots and adhering soil. Rhizobium seed inoculation was done by using effective Rhizobium leguminosarum
(Rhizobium spp.) obtained from Dept. of Soil Science, NARC Islamabad and applied. The seeds were coated with gum acacia and $10 \mathrm{~kg}$ pot $^{-1}$ soil was used. Soil used during the experiment was collected from the University of Peshawar. The soil was air-dried, sieved (4 mm) and characteristics determined at soil laboratory of the department of Soil and Environmental Science, The University of Agriculture, Peshawar. Characteristics of the soil included soil texture as sandy loam, organic matter $6.65 \%$, nitrogen $0.044 \%$ and phosphorus $1.13 \%$ [16]. The $\mathrm{pH}$ of saturated paste (7.30) was determined. Seeds were inoculated individually with Rhizobium and AM fungi (applied as layering on soil surface) and combination of both and different levels rock phosphate fertilizer. The plants were irrigated with tap water as and when required. The plants were collected from each replication for sampling at vegetative, flowering and fruiting after sowing. Plant height, pods plant ${ }^{-1}$ and seeds $\operatorname{pod}^{-1}$ data were recorded on $45^{\text {th }}$ day. The following treatments were used in the study. $\mathrm{T} 1=$ Control (Un inoculated)

T2 =Inoculation with VAM fungus alone

T3 =Inoculation with Rhizobium alone

T4 =Inoculation with Rhizobium + VAM (Dual inoculation)

T5 =Application with Rock phosphate alone T6 =Inoculation with Rock phosphate + VAM (Dual inoculation)

T7 =Inoculation with Rhizobium + VAM + Rock phosphate

Spore density

\section{Statistical analysis}

Experimental data were statistically analyzed by subjecting the data to analysis of variance (ANOVA) technique, the means were subjected to LSD test and differences among treatments were determined at $\mathrm{p} \leq 0.05$ using the Statistical Analysis System (SAS) [17] program [18]. 


\section{Results and discussions \\ Plant height}

The ANOVA revealed highly significant differences among the treatments for plant height at harvesting stage. Results of VAM, RHZ, RHZ+VAM, RP and VAM+RP inoculation on plant height of Pisum sativum (Tables 1-2 and Fig.1). It is evident from the data VAM+RP and RHZ+VAM enhanced the plant height compared to the control. Results match with [19]. that Dual and triple inoculation (co-inoculation) of microbes (bioagents) has beneficial effects on plant growth and development. Although, dual inoculation had good response but triple inoculation also exhibited significant positive response on growth of E. saligna seedlings. Mixed VAM + Rhizobium $+\mathrm{RP}$ had more increase in height. Our results correlate with the findings of [20-21]. that both rhizobial and mycorrhizal symbioses can act synergistically on promoting plant growth. Our results also agree with the findings of [22]. who stated that treatments which included rock phosphate (RP) and seed treatment with phosphate solubilizing bacteria (PSB) and Rhizobium application $\mathrm{RP}+\mathrm{PSB}+$ Rhizobium recorded higher values of growth parameters including plant height, number of branches per plant, number of seeds per plant and pod length. Our results are also in-line with the findings of [23-26]. The lowest plant height was recorded in control treatment as evident from data in (Tables 1-2 and Fig.1). Our findings are further in-line with [27]. who also reported significant effects for plant height VAM+RP and RHZ+VAM produced the highest plant height which was higher than control treatment (control) in Pisum sativum. This result was in agreement with that of [28] where it was reported that plant height of soybean was highest with $20 \mathrm{~kg} \mathrm{P}$ ha- ${ }^{-}$. Same observation by [29] that synergistic effects of the combined application of rhizobia and AM fungi enhance plant growth to a greater extent than singular inoculation. The plant height was increased with the RP+VAM+Rhz. reached to maximum compared to the treatment of each of them alone as shown in Table1-2. Our finding match with [29] who studied the influence of phosphorus fertilization and Rhizobium inoculation on growth and yield parameters of mungbean (Vigna radiata).

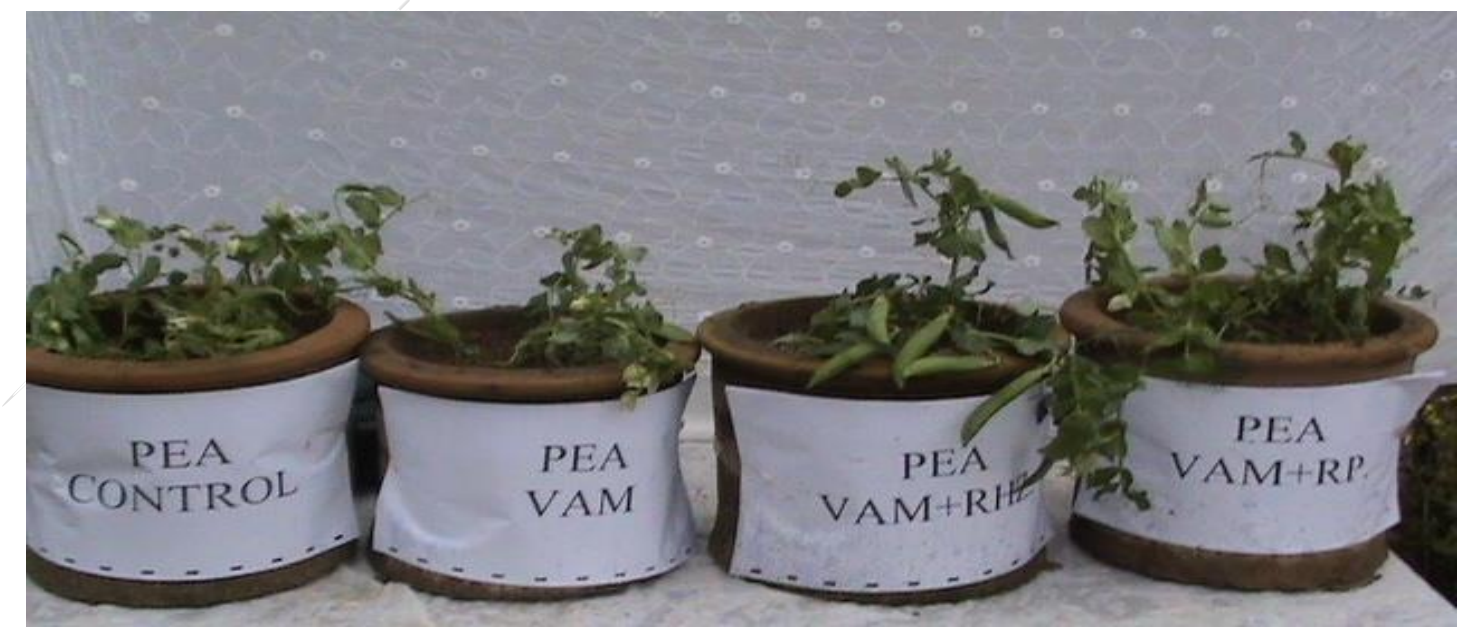

Figure 1. Effect of VAM, VAM+RHZ and VAM+RP inoculation on pods per plant of Pisum sativum 


\section{Number of leaves plant ${ }^{-1}$}

Data regarding number of leaves plant ${ }^{-1}$ revealed highly significant differences for bio-fertilizer treatments. Mean values for number of leaves plant ${ }^{-1}$ at different biofertilizer are given in Tables (1-2). Significance of RP+VAM+Rhz effect shows an observable effect on number of leaves plan $^{-1}$. Our results are in accordance with [30] who studied the effect of bio-fertilizers on the growth and yield of green gram (Vigna radiata). Our results are according to [31] who reported that the effect of seed inoculation with Rhizobium and phosphate solubilizing bacteria. $\mathrm{Rh}+\mathrm{PSB}$ significantly increased plant height, number of branches, number of leaves and leaf area.

\section{Number of pods per plant}

The ANOVA for number of pods plant ${ }^{-1}$ showed highly significant differences among bio-fertilizer treatments at harvesting stage. Our results are in agreement with that of [9] who reported that combined inoculation of $G$. intraradices with $P$. straita plus Rhizobium to pathogen inoculated plants caused greater increase in plant growth and number of pods than by inoculation of $G$. intraradices plus Rhizobium or G. intraradices plus P. straita alone. Same finding were reported by [32] that combined inoculation of VAM fungus, Glomus macrocarpum and Bradyrhizobium japonicum in soybean variety William 82 promoted maximum growth and yield. Our result showed that VAM produced significantly better growth attributes when combined with RP or Rhz as compared to the yield and yield attributes over rest of the biofertilizers and fertilizer (RP) alone. Our result are also in-line with [33] who reported the effect of seed inoculation with Rhizobium along with various levels of phosphorus on chickpea (cv. Karak-1) growth through significant increase in pods/ plant.

\section{Pod length}

Analysis of variance regarding pod length depicted highly significant differences among bio-fertilizer treatments at fruiting stage. Mean values at VAM, RHZ, RHZ +VAM, RP and VAM+RP+Rhz. inoculation on number of podsplant ${ }^{-1}$ of Pisum sativum following seven treatments are given in Tables (1-2).Maximum pod length was observed at RHZ +VAM (Tables 1-2). Our results agree with [34] who reported that dual inoculation, Rhizobium and VAM resulted in increase in grain yield, over no inoculation for the yield of green gram, viz., pods per plant, pod length, seeds per pod.

\section{Number of seeds per pod}

Highly significant differences were observed among treatments for number of seeds pod1at harvesting stage. The highest numbers of seeds pod- ${ }^{1}$ were found in VAM+Rhz and VAM treatment which was higher than that of control plants shown in Tables 1-2 and Fig.1. Our results agree with [34] who concluded that dual inoculation, rhizobium and VAM resulted in increase in grain yield, over no inoculation. Our results are further supported by the findings of [35] reported that the percentage increase in grain yield over control was observed to be significantly higher in plants inoculated with Rhizobium strains and phosphate solubilizing bacteria. Similar results were obtained by [22] who stated that treatments which included rock phosphate (RP) and seed treatment with phosphate solubilizing bacteria (PSB) and Rhizobium application of RP and $+\mathrm{PSB}+$ Rhizobium recorded higher values of growth as well as yield. Our results are also supported by [36] who found that dual inoculation of rhizobium + VAM was superior over single inoculation. 
Table 1. Mean square values for plant height $\left(\mathrm{PH}_{1}\right)$, number of leaves $\left(\mathrm{NL}_{1}\right)$ at flowering stage, plant height $\left(\mathrm{PH}_{2}\right)$, number of leaves $\left(\mathrm{NL}_{2}\right)$, number of flowers at flowering stage, plant height $\left(\mathrm{PH}_{3}\right)$, number of leaves $\left(\mathrm{NL}_{3}\right)$, number of pods plant ${ }^{-1}$, pod length and number of seed pod $^{-1}$ for different bio-fertilizer treatments

\begin{tabular}{llllllllllll}
\hline SOV & DF & PH $_{\mathbf{1}}$ & \#Lv $_{\mathbf{1}}$ & PH $_{\mathbf{2}}$ & \#Lv & \#Flower & PH $_{\mathbf{3}}$ & \#Lv & \#Pod/plnt & Pod Lnth & \# seed \\
\hline Rep & 4 & 12.1407 & 1.6714 & 3.3919 & 0.1714 & 0.38571 & 2.9079 & 8.1857 & 0.61429 & 1.93614 & 0.7571 \\
Treat & 6 & 6.0218 & 10.1905 & 43.0598 & 95.8476 & 0.79048 & 24.1750 & 11.1333 & 3.36190 & 0.86181 \\
Error & 24 & 3.3887 & 4.4881 & 4.0305 & 5.9548 & 0.71905 & 1.0344 & 3.4190 & 1.56429 & 0.36264 & 2.8405 \\
\hline CV & & 16.03 & 11.98 & 6.82 & 18.41 & 0.71905 & 3.09 & 9.15 & 33.16 & 10.20 & 28.36 \\
\hline
\end{tabular}

Table 2. Mean values for plant height (PH1), number of leaves ( $\left.\mathrm{NL}_{1}\right)$ at flowering stage, plant height $\left(\mathrm{PH}_{2}\right)$, number of leaves $\left(\mathrm{NL}_{2}\right)$, number of flowers at flowering stage, plant height $\left(\mathrm{PH}_{3}\right)$, number of leaves $\left(\mathrm{NL}_{3}\right)$, number of pods plant ${ }^{-1}$, pod length and number of seed pod $^{-1}$ for different bio-fertilizer treatments

\begin{tabular}{|c|c|c|c|c|c|c|c|c|c|c|}
\hline Treat & $\mathbf{P H}_{1}$ & $\# \mathbf{L v} \mathbf{v}_{1}$ & $\mathbf{P H}_{2}$ & \#Lv 2 & \#Flower & $\mathrm{PH}_{3}$ & $\# \mathbf{L} \mathbf{v}_{3}$ & \#Pod/plnt & Pod Lnth & \# seed \\
\hline T1 & $9.780 \mathrm{~b}$ & $15.600 \mathrm{c}$ & $29.480 \mathrm{~b}$ & $18.000 \mathrm{ab}$ & $4.6000 \mathrm{a}$ & $31.560 \mathrm{~b}$ & $18.200 \mathrm{c}$ & $3.0000 \mathrm{~b}$ & $5.4000 \mathrm{~b}$ & $3.2000 \mathrm{c}$ \\
\hline $\mathbf{T} 2$ & $11.280 \mathrm{ab}$ & $16.400 \mathrm{bc}$ & $33.800 \mathrm{a}$ & $19.800 \mathrm{a}$ & $4.4000 \mathrm{a}$ & $34.600 \mathrm{a}$ & $21.200 \mathrm{ab}$ & $3.4000 \mathrm{ab}$ & $5.9000 \mathrm{~b}$ & $7.0000 \mathrm{ab}$ \\
\hline T3 & $12.260 \mathrm{a}$ & $18.800 \mathrm{ab}$ & $27.900 \mathrm{bc}$ & $10.600 \mathrm{c}$ & $5.4000 \mathrm{a}$ & $35.220 \mathrm{a}$ & $19.600 \mathrm{bc}$ & $4.2000 \mathrm{ab}$ & $5.9400 \mathrm{~b}$ & $5.8000 \mathrm{ab}$ \\
\hline T4 & $11.220 \mathrm{ab}$ & $18.600 \mathrm{ab}$ & $32.960 \mathrm{a}$ & $15.200 \mathrm{~b}$ & $5.0000 \mathrm{a}$ & $35.660 \mathrm{a}$ & $22.600 \mathrm{a}$ & $4.2000 \mathrm{ab}$ & $6.7600 \mathrm{a}$ & $7.8000 \mathrm{a}$ \\
\hline T5 & $10.860 \mathrm{ab}$ & $17.000 \mathrm{abc}$ & $25.700 \mathrm{c}$ & $8.800 \mathrm{c}$ & $4.6000 \mathrm{a}$ & $30.020 \mathrm{c}$ & $19.000 \mathrm{bc}$ & $2.6000 \mathrm{~b}$ & $5.7800 \mathrm{~b}$ & $5.2000 \mathrm{bc}$ \\
\hline T6 & $11.740 \mathrm{ab}$ & $17.800 \mathrm{abc}$ & $28.500 \mathrm{~b}$ & $9.800 \mathrm{c}$ & $4.8000 \mathrm{a}$ & $31.220 \mathrm{bc}$ & $19.800 \mathrm{bc}$ & $4.0000 \mathrm{ab}$ & $5.7800 \mathrm{~b}$ & $6.4000 \mathrm{ab}$ \\
\hline T7 & $13.260 \mathrm{a}$ & $19.600 \mathrm{a}$ & $27.700 \mathrm{bc}$ & $10.600 \mathrm{c}$ & $5.4000 \mathrm{a}$ & $32.420 \mathrm{~b}$ & $21.000 \mathrm{ab}$ & $5.0000 \mathrm{a}$ & $5.7800 \mathrm{~b}$ & $6.2000 \mathrm{ab}$ \\
\hline Mean & 11.486 & 17.686 & 29.434 & 13.257 & 4.8857 & 32.957 & 20.200 & 3.7714 & 5.9057 & 5.9429 \\
\hline LSD & 2.4029 & 2.7653 & 2.6206 & 3.1853 & 1.1069 & 1.3276 & 2.4136 & 1.6326 & 0.7861 & 2.2000 \\
\hline
\end{tabular}

Table 3. Pea (V5) all values mean \pm SEM of 3 determinations (replicates)

\begin{tabular}{|c|c|c|c|c|c|c|c|c|c|c|c|c|}
\hline Treat & Vegetative & stage* $^{*}$ & & & & Fruitin & g stage*** & & Flowerin & stage $^{* * * *}$ & & \\
\hline Biofer & $G l 1$ & Scl1 & $A c 1$ & Totl.\# & $G l 2$ & $\mathrm{Scl} 2$ & $A c 2$ & Totl.\# & $G l 3$ & Scl3 & $A c 3$ & Totl.\# \\
\hline Control & $29.67 \pm 0.84$ & $5 \pm 0.33$ & $1 \pm 0.33$ & $35.67 \pm 0.19$ & $44.67 \pm 1.50$ & $3.33 \pm 0.33$ & $1 \pm 0.33$ & $45.67 \pm 0.69$ & $46.67 \pm 1.26$ & $2.67 \pm 0.38$ & $1.33 \pm 0.1$ & $50.33 \pm 1.64$ \\
\hline VAM & $51.33 \pm 1.07$ & $7.33 \pm 1.17$ & $2.00 \pm 0.33$ & $59.67 \pm 1.50$ & $50.00 \pm 0.33$ & $5.00 \pm 0.88$ & $1.67 \pm 0.19$ & $56.67 \pm 1.35$ & $60 \pm 5.04$ & $7.33 \pm 2.14$ & $1.67 \pm 0.19$ & $84 \pm 0.00$ \\
\hline RHZ. & $51.67 \pm 1.17$ & $4.67 \pm 0.19$ & $3.00 \pm 0.88$ & $59.33 \pm 1.35$ & $54.00 \pm 0.67$ & $7.00 \pm 0.33$ & $2.33 \pm 0.19$ & $63.33 \pm 0.38$ & $68.33 \pm 3.56$ & $6.67 \pm 0.38$ & $1.00 \pm 0.58$ & $76.00 \pm 3.48$ \\
\hline VAM+RHZ & $53.33 \pm 0.96$ & $8.67 \pm 1.26$ & $2.67 \pm 0.38$ & $64.67 \pm 2.34$ & $59.33 \pm 1.50$ & $7.33 \pm 1.39$ & $2.33 \pm 0.19$ & $69.00 \pm 1.33$ & $71 \pm 1.45$ & $8.33 \pm 1.58$ & $2.67 \pm 0.19$ & $82 \pm 3.00$ \\
\hline RP115gm & $33.00 \pm 0.67$ & $5.33 \pm 0.69$ & $2.33 \pm 0.19$ & $40.67 \pm 0.51$ & $48.67 \pm 0.38$ & $1.67 \pm 0.96$ & $3.67 \pm 0.19$ & $54.00 \pm 1.15$ & $52.00 \pm 0.33$ & $4.00 \pm 0.33$ & $1.67 \pm 0.51$ & $57.67 \pm 0.19$ \\
\hline MRP130gm & $44.33 \pm 0.19$ & $4.33 \pm 0.51$ & $1.67 \pm 0.38$ & $50.33 \pm 0.69$ & $55.00 \pm 0.67$ & $4.00 \pm 0.33$ & $3.00 \pm 0.33$ & $62.33 \pm 1.07$ & $59.33 \pm 0.69$ & $4.67 \pm 0.51$ & $2.00 \pm 0.33$ & $66.00 \pm 0.58$ \\
\hline MRP $_{2} 60 \mathrm{gm}$ & $50.00 \pm 0.67$ & $4.33 \pm 0.45$ & $1.67 \pm 0.51$ & $55.67 \pm 0.38$ & $57.00 \pm 1.07$ & $5.00 \pm 1.20$ & $2.67 \pm 0.33$ & $64.67 \pm 0.19$ & $59.33 \pm 0.84$ & $4.67 \pm 0.69$ & $2.00 \pm 0.33$ & $66.00 \pm 0.58$ \\
\hline
\end{tabular}




\section{Spore density}

In the present work soil was collected from different pots with plants at three different stages of growth. Three genera of endogonaceous spores were identified which were Glomus mosseae, G.aggregatum and G.fasiculatum, Acaulospora mellae, A.rehmii, and Sclerocystis clavispora, S. taiwanensis species. Quantitative distribution of VAMF spores at three different stages of the host showed variations. Average number of spores counted per $100 \mathrm{gms}$ of soil was different in terms of increase from plant to plant, variety to variety and stage to stage showed in Table(3) and Figure (2,). Their number increased gradually from vegetative stage to fruiting stage. Our findings are in agreement with the [37-38] who investigated that genus Glomus is a predominantly distributed genus in the soil all over the world and was most efficient and produced statistically higher mycorrhizal colonization than other mycorrhizal fungi also agree with the report of [39] who stated the influence of AM fungi on growth indices revealed that $G$. mosseae was the more effective fungus in stimulating peanut growth when compared with G. fasciculatum.

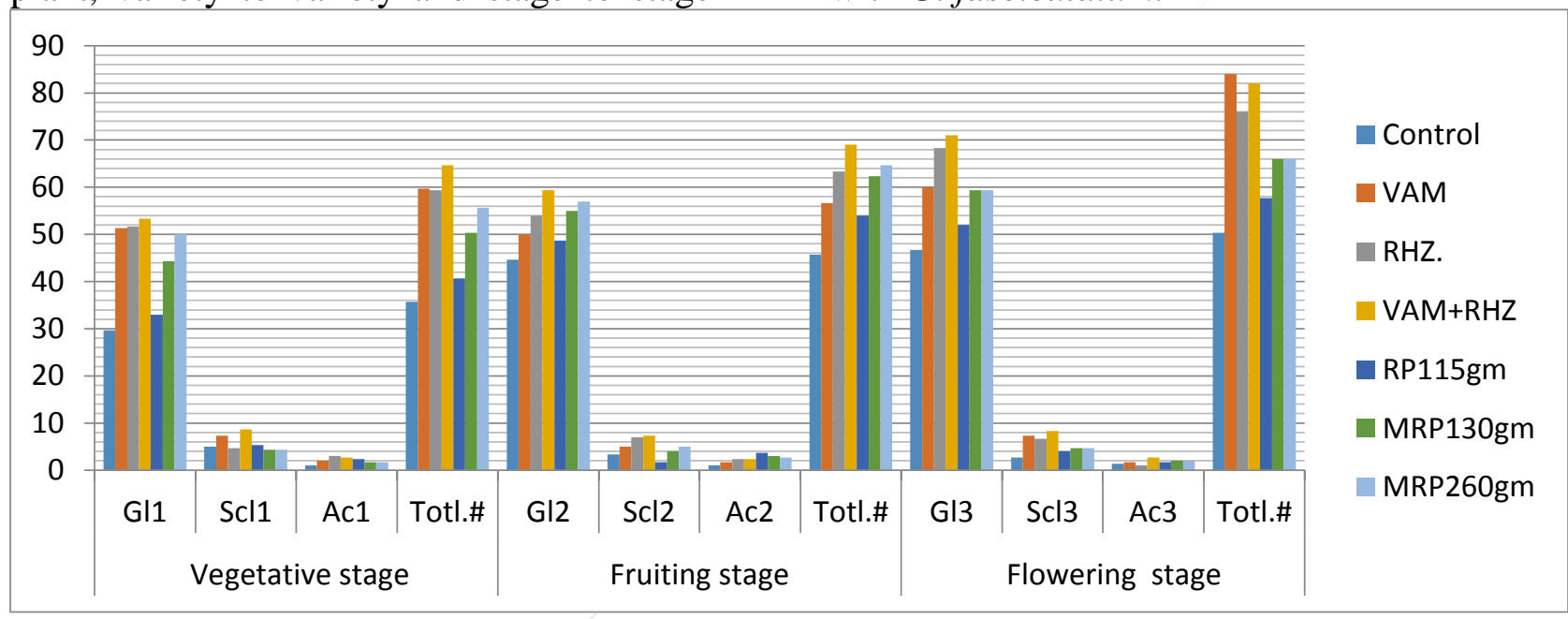

Figure 2. Gl. (Glomus species),Scl.(Sclerocystis spp.),Ac.(Aculospora spp) Effect of VAM, VAM+RHZ and VAM+RP inoculation on spores density at three growth stages. Key: (1,for vegetative stage, 2 for flowering stage and 3 for fruiting stage)

\section{Conclusion and recommendations}

An experiment was conducted at the Department of Botany, University of Peshawar Pakistan to study the effect of different bio-fertilizer treatments on growth of Pea. Seven treatments were applied including Control, VAM, Rhizobium, Rhizobium+VAM, Rock phosphate, Rock phosphate+VAM and Rock phosphate+VAM+Rhz. Rock phosphorus fertilization alone, application along with VAM and rhizobium inoculation increased the growth parameters significantly. Maximum number of pods plant $^{-1}$ were observed where VAM along with rhizobium inoculation were applied. It is concluded that Pisum sativum should preferably be grown with dual inoculation of VAM along with rhizobium and rock phosphate. Quantitative distribution of VAMF spores at three different stages of the host showed variations, in terms of increase from plant to plant, variety to variety and stage to stage.

\section{Authors' contributions}

Conceived and designed the experiments: $\mathrm{T}$ Yaseen \& $F$ Hussain, Performed the experiments: T Yaseen, Analyzed the data: $\mathrm{T}$ Yaseen, Contributed reagents/ materials/ analysis tools: T Yaseen \& M Shakeel, 
Wrote the paper: $\mathrm{T}$ Yaseen

\section{References}

1.Bonfante P \& Genre A (2008). Plants and arbuscular mycorrhizal fungi: an evolutionary-developmental perspective. Trends Plant Sci. 13:492-498.

2.Feddermann N, Finlay $R$, Boller $T$ \& Elfstrand M (2010). Functional diversity in arbuscular mycorrhiza - the role of gene expression, phosphorous nutrition and symbiotic efficiency. Fungal Ecol. 3: 1-8.

3.Smith SE, Facelli E, Pope S \& Smith FA (2010). Plant performance in stressful environments: interpreting new and established knowledge of the roles of arbuscular mycorrhizas. Plant and Soil 326: 3-20.

4.Chalk PMR, Souza de F, Urquiaga S, Alves BJR \& Boddey RM (2006). The role of arbuscular mycorrhiza in legume symbiotic performance. Soil Biol Bioch 38: 29442951.

5.Akhtar MS \& Siddiqui ZA (2009). Effects of phosphate solubilizing microorganisms and Rhizobium sp. on the growth, nodulation, yield and root-rot disease complex of chickpea under field condition. Afri J Biotech. 8(15): 3489-3496.

6.Jain AK, Kumar S \& Panwar JDS (2007). Role of Rhizobium, phosphorus and micronutrients on growth and modulation of green gram (Vigna radiata (L.) Wilczek). Adv Plant Sci. 20 (2): 337-339.

7.Kushwaha HS (2007). Response of chickpea to bio-fertilizers, nitrogen and phosphorus fertilization under rainfed environment. J Food Legumes. 20(2): 179181.

8.Jain AK, Kumar S \& Panwar JD (2008). Effect of phosphorus and micronutreints with seed inoculation on green gram (Vigna radiata (L.) Wilczek). Adv Plant Sci. 21(1): 295-297.

9.Jain AK, Kumar S, Panwar JDS \& Jain R K (2009). Seed vigour affected by phosphorus and micronutrients with Rhizobium inoculation in mung bean (Vigna radiate). Adv Plant Sci.22(1): 309-310

10. Pir FA, Nehvi FA, Abu-Manzar, Dar SA, Allai BA (2009). Integrated phosphorus management in mungbean in Kashmir valley. Trends in Biosci.2 (2): 25-26.

11. Rahman MK, Kabir SM, Mohsin GM, Alam MD \& Mandal R (2008). Effects of inoculation with arbuscular-mycorrhizal fungi and phosphorus on growth, yield and nutrient uptake of mungbean grown in sterile and non-sterile soil. $J$ Phytol. 21(2): 247-251.

12. Ray JG \& Valsalakumar N (2009). Arbuscular Mycorrhizal Fungi and Piriformo spora indica individually and in combination with Rhizobium on green gram. J Plant Nut. 21: 3-4.

13. Singh PK \& Singh AK (2010). Response of mungbean (Vigna radiata L. Wilczek) in relation to micronutrients content and yield as affected by sulfur and cobalt application. Envi and Ecol. 28(1B): 564568.

14. Thenua OVS, Singh SP \& Shivakumar BG (2010). Productivity and economics of chickpea (Cicer arietinum) fodder sorghum (Sorghum bicolor) cropping system as influenced by $\mathrm{P}$ sources, biofertilizers and irrigation to chickpea. Indian

15. Murat E, Demir S, Tufenkci EOS, Oguz F \& Akkopru A (2011). Effects of Rhizobium, arbuscular mycorrhiza and whey applications on some properties in chickpea (Cicer arietinum L.) under irrigated and rainfed conditions. Field Crops Research.122 (1): 14-24.

16. Isen SR \& Sommers LE (1982). Potassium In: A.L.Page ,R.H.Miier and D.R.Keeney (eds.).Method of Soil Analysis. Analysis. Part 2 Agronomy 9. America Society of Agron Madison, W1. 403-427. 
17. SAS (1998). Statistical analysis software, version 6.12. SAS Institute, Cary NC, USA

18. Khan IA, Ayub N, Mirza SN, Nizam SM \& Azam M (2008). Synergistic effect of dual inoculation (Vesicular-Arbuscular Mycorrhizae) on the growth and nutrients uptake of Medicago sativa Pak J Bot 40(2): 939-945.

19. Talaat NB \& Abdallah AM (2008). "Response of Faba Bean (Vicia fava L.) to Dual Inoculation with Rhizobium and VA Mycorrhiza under Different Levels of $\mathrm{N}$ and P Fertilization," Journal of Applied Sciences Research. 4(9): 1092-1102.

20. Jia Y, Gray VM \& Straker CJ (2004). The influence of Rhizobium and arbuscular mycorrhizal fungi on nitrogen and phosphorus accumulation by Vicia faba. Ann Bot. 94:251-258.

21. Bhuiyan MAH (2004). Evaluation of introducing mungbean into cereal based cropping pattern for sustainable soil fertility and productivity. Ph. D. Thesis, Dept of Soil Sci, Bangladesh Agril Univ, Mymensingh, Bangladesh 1-2 17.

22. Jarande NN, Mankar PS, Khawale VS, Kanase AA \& Mendhe JT (2006). Response of chickpea (Cicer arietinum L.) to different levels of phosphorus through inorganic and organic sources. $J$ Soils and Crops. 16(1): 240-243.

23. Rajasekaran S \& Nagarajan SM (2005). Effect of dual inoculation AM fungi and Rhizobium on chlorophyll content of Vigna unguiculata (L.) Walp var Pusa 151. Mycorrhiza 17(1): 10-11.

24. Mortimer PE, Pérez-Fernández MA \& Valentine AJ (2008). The role of arbuscular mycorrhizal colonization in the carbon and nutrient economy of the tripartite symbiosis with nodulated Phaseolus vulgaris. 40 (5): 1019-1027.

25. Nishita G \& Joshi NC (2010). Growth and yield response of chick pea (Cicer arietinum) to seed inoculation with
Rhizobium sp. Nature and Sci. 8(9): 231236.

26. Nazir H, Hassan B, Habib R, Chand L, Ali A \& Hussain A (2011). Response of bio-fertilizers on growth and yield attributes of blackgram. Inter J Current Research. 2 (1): 148-150.

27. Hani A, AL-Zalzaleh, Majid A, Mathew AR (2009). VAF Inoculation for selected ornamental plants in bioremediated and agricultural soils. Eur J Sci. 25 (4): 559566.

28. Shivakumar BG \& Sidramappa SN (2004). Influence of sources and levels of phosphorus with and without phosphorus solubilizing bacteria (PSB) seed treatment on growth and yield of soybean. Ann Agri. 25 (2): 333-334.

29. Hussain J, Ullah R, Rehman NU, Khan AL, Muhammad Z, Khan FU, Hussain ST \& Anwar S (2010). Endogenous transitional metal and proximate analysis of selected medicinal plants from Pakistan. J Medi Plants 4(3):267-270.

30. Gilani SN \& Bharose R (2004). Effect of bio-fertilizers on the enrichment of soil fertility with special reference to soil phosphorus status and its effect on yield of green gram (Vigna radiata L.). New Agric 15(1/2): 129-131.

31. Balachandran S, Deotale RD, Hatmode CN, Titare PS \& Thorat AW (2005). Effect of bio-fertilizers (pressmud, Rhizobium and PSB) and nutrients (NPK) on morpho-physiological parameters of green gram. J Soils and Crops. 15(2): 442-447.

32. Jalaluddin M (2005). Effect of inoculation with VAM fungi and Bradyrhizobium on growth and yield of soybean in Sindh. Pak J Bot. 37(1): 169173.

33. Khan MSS, Latif A, Rafique M, Sajjad T \& Perveen L (2005). Effect of seed inoculation and phosphorus fertilizer on 
yield of chickpea in semi-arid areas of NWFP. Indus J Plant Sci. 4(4): 591-594.

34. Jagvir S, Deshmukh MS \& Tandulkar NR (2004). Direct and Residual effect of sulphur in cotton-wheat cropping system in sandy soil. Fertilizer News 49: 61-63.

35. Chatterjee A \& Bhattacharjee P (2002). Influence of combined inoculation with Rhizobium and phospho bacteria on mungbean in field. J Mycopath. 40(2): 201-203.

36. Meghvansi MK \& Mahna SK (2009). Evaluating the symbiotic potential of Glomus intraradices and Bradyrhizobium japonicum in vertisol with two soybean cultivars. Ameri Eurasian J Agron. 2 (1): 21-25.
37. Ampofo K \& Twum (2008). Growth response of Gliricidia sepium (jacq.)walp to inoculation with different arbuscular mycorrhizal (AM) fungi. Journal of Science and Technology. 28 (2)54-60.

38. Fatma T, Suriyakup P, Vailhe H, Jansa J \& Drevon JJ (2009). Assess suitability of hydroaeroponic culture to establish tripartite symbiosis between different AMF species, beans, and rhizobia. BMC Plant Biology. 9:73.

39. Abdulla S \& Al-Khaliel (2010). Effects of Arbuscular Mycorrhization in sterile and non-sterile soils. Tropical Life Sciences Research 21(1):55-72. 